\title{
FORMAS DE CRIAÇÃO DE GADO NO ARQUIPÉLAGO MALAIO
}

\author{
Josefine Huppertz
}

O Arquipélago Malaio ou Insulíndia estende-se, de ambos os lados do equador, entre a Ásia e a Austrália, não apresentando senão ligeiras variações do ponto de vista do clima, sobretudo no tocante às condições de temperatura. Chuvas abundantes possibilitam a existência de exuberantes florestas virgens na parte ocidental do arquipélago, ao passo que a porção oriental de Java, a ilha de Madura e as pequenas ilhas da Sonda são dominadas de extensas savanas, conseqüência da estiagem aí provocada, no fim do verão, pela monção sueste, relativamente sêca em virtude da proximidade da Austrália.

Desde as invasões dos pré-malaios vindos do continente asiático, que (por exemplo, os Batak de Sumatra) praticam a cultura de queimada ou milpa com arroz das montanhas (ladang) e a criação de por$\cos$, a primitiva população ilhéia foi rechaçada pouco a pouco para as florestas ínvias do interior, onde continuam vivendo ainda hoje como primitivos coletores (entre êles, os Kuba e Mana de Sumatra). As populações mais jovens, de imigração mais recente, os "malaios costeiros", fortemente mongolizados e de cultura achinesada, dedicam-se à lavoura e criação de gado de porte. Em conseqüência da penetração da altacultura hindu deram origem a esplêndidas paisagens culturais com campos de arroz artificialmente irrigados (sawahs). A cultura brâmane, proveniente da Índia Anterior, bem como de influências budistas fizeram surgir em Java e Bali grandes reinos, dos quais ainda hoje nos falam expressivos monumentos de arte. Partindo de Málaca, o Islão avançou até Java como potência conquistadcra, mas também favorecendo o desenvolvimento cultural, até ser, por sua vez, superado pelo Cristianismo. Povos europeus vieram substituir o comércio árabe, entre êles principalmente os holandeses que, graças à sua colonização, contribuiram para o grande progresso econômico particularmente de Java. Esta ilha, com seus 52 milhões de habitantes, é hoje a região mais densamente povoada da Indonésia, cuja população total é avaliada em cêrca de 80 milhões de habitantes. Sumatra, que do ponto de vista geológico e climatológico apresenta as mesmas condições de Java, sòmente desde tempos mais recentes vem sendo submetida a uma colonização mais intensa, tendo ficado, por isso, em situação de considerável atraso econômico e cultural em comparação com Java. Prova êste fato que não só o meio-ambiente, mas também o desenvolvimento histórico-cultural influem nas funções decisivas de um país.

Vindo sobrepor-se à vida econômica dos ilhéus, as culturas invasoras não sòmente levaram à substituição, em muitos pontos, da pri- 
mitiva economia coletora e da lavoura a enxada pela cultura de arado, como ainda modificaram, em vários aspectos, as formas de criação de gado entre os naturais. Outrora os animais, especialmente os porcos, sempre existentes em grande número, se criavam soltos na aldeia, pegando-se de caso em caso os que se destinavam à ceva ou à matança (como se observa entre lavradores a enxada, que não conhecem a criação de gado de porte). Tal sistema foi substituido, de modo mais ou menos generalizado, pelas formas econômicas mais intensivas da criação de gado de porte em currais ou estábulos, ligados nessas regióes à lavoura a arado. Característica da criação em estábulos é o fornecimento de forragem aos animais, ao passo que entre os lavradores que, tendo criação, conservam o gado em currais, êste é obrigado a procurar o alimento nas pastagens e nas restevas (Huppertz 1951, 39).

As regiões densamente povoadas apresentam, nos quadros do seu sistema econômico mais intensivo, outras formas de criação de gado que as fracamente povoadas e de economia extensiva. No primeiro caso impõe-se a criação em estábulos, ao passo que no segundo quase sempre se criam soltos pela aldeia os animais, em geral de pequeno porte.

\section{Criação de animais soltos}

As populações que se formaram sedentarias, dedicando-se apenas à lavoura em pequena escala, criam os porcos soltos pela aldeia. Os animais passam as noites debaixo das habitações em palafitas ou nas ruas das povoações, sem que lhes caiba lugar fixo. A forragem regular é desconhecida, mormente em vista do fato de não haver vantagens na criação sistemática, por ser grande a oferta de animais semi-domesticados. Os porcos são capturados e abatidos segundo as necessidades. Assim, o negritos das Filipinas, localizados nas regiões montanhosas e cobertas de florestas, praticam, ao lado da milpa, também, em certa escala, a criação de porcos soltos nas aldeias. Por ocasião de solenidades religiosas, os animais são imolados a título de sacrifício e depois consumidos (Kolb 1942, 129). Já entre os lavradores que adotam o sistema de terraços, radicados nas zonas mais baixas, a criação de gado de porte se reveste de importância maior. No entanto, também neste caso é ainda o porco sôlto o animal doméstico mais importante. De dia, anda livre pelas ruas, alimentando-se de restos. Sòmente à noite. volta para abrigar-se debaixo das habitações em palafitas. Também entre os Alfur de Sulawesi, na medida em que não sofreram influências muçulmanas, o porco vive, como animal de abate mais importante, no sistema da criação sôlta. O mesmo vale das tribcs malaias de Kalimentan (os Dajak) e de Sumatra, que praticam a cultura da enxada.

\section{Criação em currais}

Onde quer que a população do arquipélago conheça o arado, aparece também o gado de porte como animal de trabaiho e tração indis- 
pensável. No entanto, nestas regiões agrícolas, o gado de porte existe geralmente em quantidades limitadas, na medida em que se afigure absolutamente necessário ao cultivo do solo. Nas savanas, bem ao contrário, predomina a criação de gado de porte. Nas savanas situadas nos planaltos das terras dos Batak (na região da Lagoa Toba), por exemplo, há para a criação intensiva de gado condições melhores do que nas zonas agrícolas da porção setentrional de Sumatra, exploradas por um sistema de plantações modernas. Nas extensas áreas pastorís o gado de porte, isto é, o búfalo aquático (Bos bubalis var. sundaicus), o zebu (boi de Sumatra) e até o cavalo (cavalo de Batak e cavalo de Sumatra), bem como o gado pequeno, criado em maior escala, encontram alimento em quantidade suficiente (Petersen 1892, 26; Loeb 1935, 23; Helbig 1940, 144; Bakker 1940, 111). À noite, o gado pequeno é tangido até a aldeia, onde se reune debaixo das habitações em palafitas (Friedmann 1871, 318; Helbig 1933, 126), ao passo quie os búfalos e zebus são levados aos currais fora da aldeia. O número dos currais é proporcional à riqueza da respectiva comunidade.

Quase todo curral possui casa de guarda (Brenner 1894, 269), visto ser grande a ameaça dos tigres (Kempski 1924, 26). A capacidade de trabalho dos búfalos é aproveitada, principalmente, para o cultivo dos campos de arroz e milho; os animais procuram seu alimento nos canıpos e pastos próximos. Assim é que os Bątak criam aí o seu gado sem grandes despesas, vendendo-o ocasionalmente aos lavradores das regices intensivamente cultivadas de Sumatra ou Java. Quanto ao mais, aproveitam o leite de búfalo e, por vêzes, também a carne dos animais. De igual maneira, o gado de porte é criado e aproveitado nas savanas do norceste e do sul de Sulavese. As pequenas ilhas da Sonda Lombok, Sumbawa, Sumba, Timor e Flores - possuem consideráve1 criação de cavalos, provàvelmente de origem mongol-árabe, visto terem sido importados, nos séculos VII e XIII, cavalos da China e, mais tarde, da India Anterior e da Arábìa (Merkens 1930, 425 ss.).

$\mathrm{O}$ alto teor calcário do solo e, por conseguinte, do capim e das plantas de forragem em geral possibilita criação lucrativa. Os animais vivem geralmente em rebanhos semi-bravios; só de raro em raro são reuniclos $€ \mathrm{~m}$ currais, a fim de não se asselvajarem inteiramente. $\mathrm{O}$ cavalo de sândalo é o melhor resultado da criação de cavalos no Arquipélago Malaio (Müller 1921, 117; Huber 1935, 110; Lehmann H., conun. pesscal). Os cavalos Batak são hoje mais raros, de vez que antigamente muitos animais machos foram exportados para Singapura. Em Sulawesi há considerável criação de cavalos na região do Golfo de Teluk e em tôrno de Makassar. Em Java, nas regiões central e ocidental, diminuiram fortemente os cavalos Kuningan e Kedu, antigamente tão ccnhecidos. Hoje se encontra sòmente no sudoeste de Java uma diminuta criação de cavalos, visto faltarem á ilha, em consequiência da exploração intensiva do solo, as zonas pastorís necessárias. Em Sumatra o número de cavalos é insignificante. Servem geralmente como animais de tração, carga e montaria, sendo empregados atualmente 
como animais de trabalho nas plantações só na região setentrional de Sulawesi. O uso da carne de cavalo na alimentação se limita a regióes pobres em sal ${ }^{1}$.

Em Java o gado às vêzes ainda é mantido em currais, ou então fica simplesmente nas ruas das aldeias perto das habitações. Vive, portanto, em parte, segundo o sistema de criação solta, não obstante ser proibido presentemente $€ \mathrm{~m}$ Java a cultura de queimada (milpa) que se liga a êsse sistema econômico. Não se cultivam plantas de forragem; nem sequer a palha de arroz e de milho é reunida depois da colheita. $O$ próprio gado $t \in m$ de procurar o alimento durante ou após o trabalho, encontrando boa forragem na resteva. No entanto, ao esmagar a palha com as patas, causa consideráveis prejuízos, que poderiam ser evitados se a palha fôsse apanhada. Haveria então forragem suficiente para a estiagem. Em vez disso, o gado é tangido no fim do verão para os "pastos comunais", existentes em muitos lugares. São pequenas áreas que, não podendo ser irrigadas, e tendo, por isso, pouca vegetação, fornecem quantidades insuficientes de forragem para o gado. Por vêzes ocorre também que, depois do preparo do campo, o gado é vendido ou alugado a habitantes de regiões mais ricas em pastagens, mediante cessão dos bezerros ou outros pagamentos em espécie (Stipper 1921, 21; Vink 1940, 165).

\section{Criação em estábulos}

Outra forma da economia pecuária faz-se notar onde se impõe um sistema econômico mais intensivo, principalmente pela maior densidade demográfica. O gado tem o seu lugar de forragem, isto é, um estábulo. O tipo de construção não se afigura de grande importância, já que se adapta, em cada caso, ao rendimento dentro do sistema econômico geral. Animais empregados apenas no amanho da terra e no transporte de carga não necessitam de cuidados especiais, nem de estábulos de construção adequada. O rendimento, dentro do sistema econômico, é garantido mesmo pelos estábulos mais primitivos, construidos à maneira de barracas. Sòmente quando se visam a realizações especiais no terreno da pecuária é que se começa a prestar mais atenção à construção do estábulo.

Observando os vários sistemas de estábulos no Arquipélago Malaio, verificamos de um lado a existência de empreendimentos integralmente extensivos, isto é, empreendimentos pecuários primitivos que năo exigem senão despesas extremamente reduzidas. De outro lado, encontramos também empreendimentos que lembram emprêsas pecuárias modernas da Europa. Essas diversas formas de criação em estábulos adaptam-se, em cada caso, às respectivas necessidades econômicas.

Entre os habitantes do litoral de Sumatra, os búfalos são tangidos, à ncite, aos seus estábulos debaixo das habitações em palafitas. E' aí mesmo que recebem também a forragem, pois, como animais de trabalho, a sua capacidade deve ser corservada em tôdas as circunstâncias. En- 
tre os Gaja, na parte setentrional de Sumatra, por exemplo, os animais forçosamente devem ser alimentados durante o ano todo em estábulos, visto não haver, pràticamente, pastagens para o gado. O búfalo, como animal de trabalho, é indispensável ao amanho da roça. Os animais chapinham durante horas a fio pelo terreno lamacento dos campos de arroz, trabalhando-o com os seus enormes cascos (Buenning 1947, 47).

$\mathrm{Na}$ Ilha de Nias, a pecuária é exercida inteiramente em função da agricultura. Ao lado de animais miúdos se criam sòmente os animais indispensáveis ao trabalho da roça. Quase durante o ano inteiro, os habitantes lidam nos campos de sol a sol, fato típico nas áreas $€ m$ que se cultiva o arroz. Quando à noite os homens, em companhia dos animais de tração, retornam às casas, as mulheres continuam nos campos, à procura da forragem necessária que na madrugada seguinte é distribuida aos animais (Loeb 1935, 137). Também na Ilha de Nias os estábulos ficam sob as habitações em palafitas (Schroeder, 1917, 152).

Da mesma forma como em Sumatra, predomina também nas Filipinás, entre a população agrícola que se serve do arado, o empreendimento de estábulo extensivo. Os búfalos aquáticos (Bos bubalis), introduzidos da China na época dos colonizadores espanhóis, servem aos plantadores de arrcz como animais de trabalho. São mantidos em estábulos debaixo das casas em palafitas, sob a peça que serve de moradia. E' também aí mesmo que recebem a forragem. Não é com muita freqüência que se aproveita o estêrco para adubar a roça. Os habitantes limitamse à mera adubação fecal; inundações ocasionais concorrem em algumas regiões para fertilizar o solo. Em terrenos montanhosos, onde os vários campos de arroz não raro são tão pequenos que podem ser trabalhados à mão, não admitindo o emprêgo do arado, procura-se manter a fertilidade do solo apenas mediante irrigação. O reduzido número de animais de porte, mantido pelos lavradores, usam-se apenas para fins de transporte. A criação de gado de porte, com o mero fito de abate, afigurarse-ia demasiado cara para a população, mormente pela escassez de recursos próprios de forragem. Em tôda parte, no entanto, onde se possam $\mathrm{t} \in \mathrm{r}$ animais para puxar o arado, torna-se mais fácil o preparo intensivo do solo, podendo ser plantada maior quantidade de arroz, o que, por sua vez, garante melhor rendimento da criação em estábulos. Hoje em dia, a necessidade de animais de trabalho é satisfeita não só pela importação da China; a população recorre também aos grandes rebanhos de búfalos que vivem nas savanas (por exemplo na parte setentrional de Luzon).

Nas zonas costeiras de Sulawesi e Kalimantan, de maior densidade demcgráfica, existe hoje o sistema da criação em estábulos. No interior de Kalimantan, no entanto, a mata virgem tropical, até hoje quase impenetrável, impede tôda espécie de criação de gado de porte. As savanas, que com freqüência interrompem as matas de Sulawesi, favorecem a imigração e colonização e, por conseguinte, também o sistema de estábulos. Eis por que aqui a densidade demográfica de certas regiões atinge a das Filipinas (20 a 100 por $\mathrm{km}^{2}$ ). 
O sistema de estábulos é também difundido nas regiões de cultivo do milho das pequenas Ilhas da Sonda, cuja primitiva população nativa não o conheceu.

Em Java, como em Bali, onde se colhe o melhor arroz da Indonésia, a agricultura e a criação pecuária estão intimamente ligadas, já que uma depende da outra. Todo pedacinho de terra aproveitável é cultrivado. Os sawahs, pequenas roças em forma de terraços que, destinados ao cultivo do arroz, se estendem pelas montanhas a dentro até alturas considerávais, são preparados com auxílio de karbau (nome malaio para os búfalos) (Preyer 1901, 556, 574). A terra é caríssima em virtude da sua fertilidade e da elevada dsnsidade demográfica. Por isso, os lavradores de Java limitam-se à agricultura, não se dedicando muito à pecuária, que difìilmente compensaria os seus esforços, visto que as colheitas, bastante fartas graças à fertilidade do solo, se vendem com facilidade maior do que o gado. No que se refere aos animais de trabalho indispensáveis, são adquiridos em Sumatra a preços bastante baixos. Em regiões de culturas muito intensivas (por exemplo, na zona de cultivo de tabaco de Wonosobo ou nas montanhas, onde se plantam em grande escala batatas e legumes), os animais passam a noite em abrigos extremamente primitivos, feitos de alguns troncos cobertos de folhas de palmeiras ou de capim. Esses estábulos de tamanho irrisório, pelo menos segundo as nossas concepções, têm o fito de concentrarem numa área mínima uma camada grossa de estêrco, cujo emprêgo é absolutamente necessário para aumentar a produção dos campos (Helbig, comun. pessoal). E' preciso salientar que o gado é usado, nestas regiões, sòmente para fins de trabalho, não parecendo prestar-se para a economia leiteira (Huber 1935, 115). No entanto, nas partes de Java onde se cria gado leiteiro para o abastecimento da população européia, decretos especiais impõem aos proprietários dos animais a construção de estábulos melhores. $O$ aumento das despesas daí decorrente é compensado pela produção de leite. Nessas regiões devota-se maior cuidado à manutenção do gado, pertencente a raças impcrtadas da Índia e da Europa ou produto do cruzamento com raças bovinas nativas, entre estas os descendentes do banteng.

Conforme a extensão do solo cultivado, o habicante de Java possui de 2 a 4 cabeças de gado de porte, de preferência como animais de trabalho ('T Hoen 1933, 385). Atualmente não the é permitido abater os animais sem licença especial. Evita-se assim que, em vista da falta crônica $d s$ dinheiro entre cs camponeses, uma parcela do gado de trabalho seja encaminhada para os matadouros e, em consequência, parte das terras de cuitivo permaneçam inexploradas, por falta de energia animal. Os animais para matança, na medida em que se destinam à população européia, são importados em quantidadie suficiente da Austrália, de Madura e de Bali. Os natives vivem de alimentação vegetal, matando sòmente, por ccasião de festas, galos, patos e muito raramente um boi.

Em Java, não só o gado de porte, mas também as cabras se recothem de noite nos estábulos que repousam sôbre palafitas de 1 a $21 / 2 \mathrm{~m}$ de altura e aos quais se chєga por meio de pequena pinguela. Dêste mo- 
do, os animais são protegidos contra a umidade do solo e a ameaça dos tigres. A forragem consiste em folhagem de árvores e capim, a menos que pastem sob a guarda de crianças (Kempski 1924, 54; Helbig comun. escrita de 11-7-1947).

E' em Madura que se encontram os empreendimentos pecuários mais desenvolvidos do Arquipélago Malaio. Devido à pouca chuva, a produção agrícola requer abundante adubação com estêrco. Visto, porém, que a terra é arada até a última nesga cultivável, de modo a não existirem pastagens para o gado, o sistema de estábulos teve de tornar-se altamente racionalizado, o que trouxe grande progresso à pecuária. Um sistema de forragem cuidadosamente planejado e o aproveitamento racional de adubos resultam em aumento considerável da produção. Em tôda parte conhecem-se fossas em que se recolhe cuidadosamente o estêrco dos estábulos (Kempski 1924, 16). Graças a essas medidas, o solo árido recebe as necessárias substâncias químicas, garantindo-se assim boas colheitas, que se afiguram de particular importância no que tange ao milho, alimentação principal dos indígenas. Em vista da grande falta de terras, difìcilmente se cogitaria de fazer plantação para forragem; tanto maior é o cuidado com que se recolhe tudo o que sirva para alimentar o gado na estiagem (flor de milho, palha de milho, folhagem de nanga, de turi, raspas de haste de folha de coqueiro, folhagem de mandioca e de batata doce, palha de arroz cortada). (Sommerfeld $1927,96)$. Tôda a palha que se consegue é armazenada após a colheita de cereais (Stipper 1921, 521), em vez de ser esmagada pelo gado que pasta, como ocorre em Java. Ademais, mesmo antes da colheita de milho, cortam-se tôdas as plantas que prometem resultados apenas modestos, secando e armazenando-as para servirem na estiagem como alimento do gado. Secam-se também as partes verdes de várias leguminosas e os brotos do bambu, que se cortam semanalmente ('T Hoen 1933, 385). Para economizar espaço, a forragem, em vez de ser armazenada em celeiros, é depositada, muitas vêzes, sôbre o estábulo.

Reunem-se os animais em estábulos fechados, base da economia pecuária nestas regiões. Sòmente após a cclheita pode o gado pastar nos campos de arroz, ou então em áreas pouco férteis, não cultivadas, às margens dos fossos de irrigação e dos caminhos. As paredes dos estábulos, trançadas de bambu, sustentam uma cobertura que desce quase até o solo. O chão, de barro batido, tem um rêgo de escoamento para o estêrco liquefeito, que se usa como adubo. A forragem é deitada $€ \mathrm{~m}$ mangedouras relativamente altas. A fim de afugentar as moscas, mantem se acesa uma chama de combustäo lenta, que enche o estábulo de fumaça (Sommerfeld 1927, 97). O estêrco que se acumula é guardado e queimado nas proximidades do estábulo. Por vêzes é tambérn levado aós campos $€ \mathrm{~m}$ estado fresco, mas sòmente depois de certo tempo é ali empregado para a adubação. Segundo as nossas concepções, é mantido inaproveitado durante espaço de tempo muito longo. Em certas regiões de Madura não se desconhecem os fossos de estêrco liqüefeito. Antes de preparar o campo, impregna-se o adubo de estêrco liqüe- 
feito, cobrindo depois de terra com o arado. Depois da germinação da sementeira, espalha-se a cinza do estêrco por sôbre a roça. Para a adubação das plantações de tabaco empregam-se também excrementos humanos, que se acumulam nas casas, em fossos especiais. $\mathrm{Na}$ pequena Ilha de Sapudi cercam-se as terras não cultivadas e utilizadas como pastagens, obtendo-se assim o adubo necessário (Sommerfeld 1927, 104, 105).

O búfalo serve aos maduresss como animal de trabalho e é nisso que reside o seu valor principal. Graças à influência européia, adquiriram certa importância também as vacas leiteiras, que originàriamente não a tinham nem aqui, nem em outras partes do arquipélago. Para fins de prođução leiteira, empregam-se hoje raças holandesas e australianas, bem como os produtos do cruzamento dessas raças com gado nativo e hindúbritânico. No entanto, é muito rara a produção de manteiga e de queijo.

Importantíssimo fator de incremento da criação de gado são as tradicionais corridas de touros (kerapan), que se realizam todos os anos. Essa festa dos madureses, em que há muito aparato e muito humor, estimula a rivalidade entre os criadores - mais ou menos como nas touradas espanholas - pois no fim da competição cada qual deseja ver premiados os seus animais. Descrição minuciosa das corridas encontra-se nos trabalhos de K. Sommerfeld (1924, 125 ss.), P. Gunning (1926, 81 ss.) e P. Telder (1937, 124 s.). Ataviados festivamente logo de manhã cedo, os animais, em grupos de três ou quatro parelhas, são conduzidos, ao som de música, à praça da partida, que em geral mede mais de 120 metros de comprimento por 20 de largura. Aí os animais são dispostos em linhas e a corrida pode começar. Cada parêlha está atrelada a um trenó de corrida (klelés), no qual, ao sinal da partida, monta um jóquei (tukang numpak), que, por meio duma corda prêsa às ventas dos touros, guia a parêlha com mão firme. Deve ser uma situação bastante dolorosa para os animais, que dessa forma são incitados a correr o quanto podem. Sommerfeld mediu velocidades médias de 10 metros por segundo, o que é realmente extraordinário em se tratando de touros.

A importância que a criação de animais tem para os madureses se manifssta no fato de que na parte leste da ilha as moradias dos criadores são cercadas de estábulos de todos os lados, ao passo que os agricultcres possuem um estábulo só, contentando-se com 2 a 5 animais de pcrte, conforme o tamanho da propriedade (Vrijburg 1919). Brinkmann $(1923,6)$ acentua especialmente que a preocupação de melhoria da raça começa quando a criação, deixando de ser meio, se transforma em fim.

O búfalo aquático (karbau) e o zebu são encontrados principalmente entre as populações que, na Madura, em Java, Bali, Lombok e nas Filipinas, se dedicam à agricultura com arado, ao passo que nas regiões em que predomina a lavoura com enxada, como nas paisagens montanhcsas das Filipinas, em Sulawesi, Sumatra e no Arquipélago de Timor, a sua ocorrência é muitíssimo limitada.

Em época recente, os lavradores de Java que trabalham com arado passam a preferir, cada vez mais, o zebu ao búfalo aquático, por ser menos pesadão e mais resistente no calor. Só na Indonésia havia em 1951 
um total de 4.230 .000 zebus e apenas 2.600.000 búfalos. Purwokerto é o centro mais moderno da criação de gado bovino na Ilha de Java; os reprodutores são importados regularmente da Holanda.

O mapa anexo, representando a distribuição das formas de criação de gado no arquipélago malaio, mostra como estas ocorrem lado a lado em áreas bem próximas uma da outra. Alguns Batak, por exemplo, são criadores, tendo desenvolvido o sistema de currais, ao passo que as tribos vizinhas têm o gado em estábulos.

A modalidade mais primitiva de criação, associada à lavoura corn enxada, e em que os animais andam soltos na aldeia, apenas para o consumo da carne, é a que vigora entre os Negritos das regióes montanhosas das Filipinas, entre os Malaios puros no sul de Sulawesi, entre os Dajak de Kalimantan que praticam a lavoura com enxada, e também nas áreas de refúgio de Sumatra.

O sistema de currais associado à agricultura com arado permite não sòmente o consumo da carne, mas também o do leite. Essa forma de utilização dos animais se estende não sòmente pelas regiões de savanas de Sumatra e de Sulawesi, mas também pelas pequenas ilhas de Sunda (como Sumbawa, Sumba, Flores e Tímor), ocorrendo igualmente, de forma esporádica, em Java.

A economia pecuária mais intensiva é possibilitada pelo sistema de estábulos. Este aparece nas áreas nas quais, em conseqüência do cultivo racional do solo, escasseiam as pastagens, obrigando ao fornecimento de forragem aos animais. Nas áreas costeiras, densamente povoadas, de Sumatra, Kalimantan e Sulawesi é característica esta modalidade de criação; é muito espalhada em Java, e em Madura encontrámo-la em forma bem pronunciada.

Salientamos no início dêste trabalho que a economia pecuária do Arquipélago Malaio foi modificada em larga medida pela história cultural do país. Onde quer que formas de economia asiáticas e européias possibilitem colonização mais densa do país, pode desenvolver-se, concomitantemente, uma economia pecuária mais intensa do que ocorre em regiões de densidade demográfica fraca.

As populações vindas do continente asiático introduziram no arquipélago, ao lado de outros elementos culturais peculiares, o cultivo com o arado e o gado de porte. Esses elementos culturais, no entanto, como já foi explicado, não foram adotados por todos os elementos indígenas. Os habitantes primitivos retiraram-se inicialmente para o interior de suas ilhas. Sòmente nas áreas em que, pela falta de espaço, foram forçados à aceitação de formas econômicas mais intensivas, adotaram o cul. tivo com a enxada e o arado e também os animais necessários aos novos sistemas, imitando os processos de trabalho das populações vizinhas, de cultura mais desenvolvida. Em Java e Bali ocorreu em ampla escala tal processo de amalgamento de elementos antigos e novos. $\grave{A}$ agricultura mais intensiva corresponde geralmente número menor de cabeças de gado de propriedade individual. Assim, por exemplo, os pequenos lavradores em Java, região densamente povoada, possuem sòmente pou- 
cos animais, que costumam ser criados em estábulos, vivendo só periòdicamente nas pastagens, ao passo que nas regiões de exploração apenas extensiva se encontram rebanhos de gado mais numerosos. Depois de preparados os campos de arroz, no período, portanto, em que começa a escassear a forragem, os habitantes de algumas zonas - os de Lombok, por exemplo - tangem os búfalos para áreas despovoadas, distantes das suas aldeias, onde ficam quase inteiramente livres, até após a colheita, sob a inspecção de alguns poucos pastôres.

Antes de concluir, cabe-nos salientar que a pecuária se liga estreitamente a fatôres religiosos. Em Java, por exemplo, o zebu (banteng domesticado, Bos banteng) foi introduzido pelos hindus como animal de trabalho, tendo superado de longe o búfalo nativo. Ainda assim, êste último continua sendo mantido em tôda parte, venerado por todos como animal sagrado, ao passo que o zebu o é apenas pelo hindu. Conclui-se daí que antigamente o zebu não era conhecido aos ilhéus como animal doméstico e que o búfalo deve ter sido, a princípio, o único animal de uso na lavoura indígena.

\section{BIBLIOGRAFIA}

Alkema, B. en Gezemer, P. J.: Volkenkunde van Nederlandsch-Indië. Haarlem 1927.

Almanak pertanian. Djakarta 1953.

Bakker, S.: Cattle Breeding in the Netherlands Indies. Bulletin of the colonial Institute Amsterdam 1940.

Brenner, Joch. Freih. v.: Besuch bei den Kannibalen auf Sumatra. Würzburg 1894 .

Brinkmann, Th.: Arbeitsersparnis, Bodenertragssteigerung und Ertragsveredlung als Aufgaben der Nutzviehhaltung; die Entwicklungstendenzen der Rindviehhaltung im Lichte dieser Aufgaben. Edler Festschrift 1923.

Bünning, E.: In den Wäldern Nord-Sumatras. Bonn 1947.

Gunning, G. P.: Indië en Jong-Nederland. Amsterdam 1926.

Helbig, K.: Die ländlichen Siedlungen auf Sumatra. In: Die Ländlichen Siedlungen in verschiedenen. Klimazonen von Fritz Klute. Breslau 1933.

Helbig, K.: Beiträge zur Landeskunde von Sumatra. Museum für Länderkunde zu Leipzig 1940, NF 8, 135-250.

Helbig, K.: Urwaldwildnis Borneo. Braunschweig 1941.

Huber, F. L.: Tierzuchtverhältnisse in Niederländisch-Ostindien. Batavia 1935 .

Huppertz, J.: Viehhaltung und Stallwirtschaft bei den einheimischen Agrarkulturen in Afrika und Asien. "Erdkunde" Bonn V, 1951, 36-51.

Kempski: Die Viehzucht Niederländisch-Indiens. Berlin 1924. Teilabdruck aus dem Sammelwerk: "Die Landwirtschaft Niederländisch-Indiens" desselben Verfassers.

Kolb, A.: Die Philippinen. Leipzig 1942.

Iocb, E.: Sumatra its History and People. In: Wiener Beiträge zur Kulturgeschichte und Linguistik. Wien 1935, S. 1-305.

Merkens, J.: Niederländisch-ostindisches Kolonialreich. In: Stang Wirth: Tierheilkunde und Tierzucht 7. Bd. Berlin-Wien 1930.

Merkens, J.: Die Alstammung des Java-Madurarindes. Zeitschrift für Tierzüchtung und Züchtungsbiologie. Berlin 16, 1929.

Müller, M.: Die Tierzucht und ihre Bedeutung in Niederländisch Ostindien. landwirtschaftliches Jahrbuch 1921, 93-154. 
Nieuwenhuis, A. W.: Quer durch Borneo, 2 Bde. Leiden 1904.

Obst, A.: Die geogr. Grundlagen der Siedlungen auf den Philippinen. Diss. Breslau 1922 .

Petersen, J. A.: Pferde, Pferdezucht und Sport in Ost-Indien. Berlin 1892.

Preyer, A.: Die Rinder auf Java und Gesichtspunkte betreffs europäischen landwirtschaftlichen Exports nach den Kolonien. Deutsche Landwirtschaftliche Presse. Berlin 1901.

Sarasin, P. U. F.: Reisen in Celebes. 2 Bde. Wiesbaden 1905.

Schadenberg, Ales: Beiträge zur Ethnographie von Nord-Luzon. Mitt. der Anthropol. Gesellschaft Wien 1888 .

Schröder, E. E. W. G.: Nias. Leiden 1917.

Sommerfeld, K.: Kerapan auf Madoera, Deutsche tierärztliche Wochenschrift 1924.

Sommerfeld, K.: Das Madurarind. Zeitschrift für Tierzüchtung und Züchtungsbiologie. 1927, S. 65-112.

Stang Wirth: Tierheilkunde und Tierzucht. Berlin-Wien 1930.

Stippe, D. G.: Encyclopaedie van nederlandsch-Indië. Leiden 1921.

Telder, P.: De Zon Tegemoet. Amsterdam 1937.

'T Hoen, H.: De Huisdieren van den Indischen Archipel. NederlandschIndië Oud en Niuw. XVIII, 1933.

Vanoverbergh, Morice: Negritos of Northern Luzon. Anthropos 1925, 1929, 1930 .

Vanoverbergh, M.: Negritos of Eastern Luzon. Anthropos 1937, 1938.

Vatter, E.: Ata Kiwan. Unbekannte Bergvölker im tropischen Holland. (Flores). Leipzig 1932 .

Vink, G. J.: De Grondslagen van het indonesische Landbouwbodrijf. Wageningen o. J. (um 1940).

Veth, B.: Das Pferd des malaischen Archipels 1894.

Vrijburg, B.: Veeteelt en veeziekten in Nederlandsch-Indië. Weltevreden 1919.

Vrijburg, B.: Rinderzucht in Niederländisch-Ost-Indien. Jahrbuch für wissenschaftliche $u$. praktische Tierzucht 1917. S 117-132.

\section{$N O T A S$}

(1) Em 1951 havia na Indonésia 503.000 cavalos (Almanak 1953).

(2) O banteng (Bos sundaicus, boi selvagem) em estado não domesticado existe atualmente só em Kalimantan, sendo mantido em Java, em estado semi-domesticado, numa reserva a oeste de Bandung, ao passo que o banteng domesticado, o boi balinês, é criado em Bali, Lombok, na parte meridional de Sulawesi e em Timor. 